\section{Обзор современных гусеничных тракторов отечественного производства}

\author{
А. В. Занин ${ }^{1}$ \\ Петрозаводский государственный университет
}

\section{АННОТАЦИЯ}

В статье приведен обзор отечественных гусеничных лесозаготовительных тракторов. Приведены описания и технические характеристики основных моделей.

Ключевые слова: гусеничный трактор, ОАО «Онежский тракторный завод», ОАО «Алтайский трактор», лесозаготовительная техника, экологическое воздействие.

\section{SUMMARY}

In the article the review of domestic caterpillar forest procuring tractors is given. Descriptions and characteristics of the basic models are presented.

Keywords: caterpillar tractor, Onego tractor factory, Altai tractor, forest procuring engineering, ecological influence.

В отечественном лесном машиностроении созданием и производством лесозаготовительной техники до недавнего времени было занято порядка 22 предприятий, ведущую роль традиционно занимали ОАО «Онежский тракторный завод» и ОАО «Алтайский трактор». Как правило, на базе тракторов этих заводов создавалась большая часть отечественных лесозаготовительных машин.

Сегодня ситуация, сложившаяся в лесном машиностроении, может быть охарактеризована как неудовлетворительная. Экспертами отмечается снижение объема лесозаготовок в $3 \ldots 3,5$ раза, значительный износ техники (30-40\% техники работает более 5 лет) [1]. Снижение объемов вывозки древесины происходит медленнее, чем износ лесозаготовительной техники, что приводит к увеличению нагрузки и износа на единицу оставшихся тракторов [2]. Кроме того, с началом рыночных преобразований, наблюдалось катастрофическое падение темпов производства лесозаготовительной техники по всей номенклатуре выпускаемой продукции. Так, например, за последнее десятилетие на ОАО «ОТЗ» выпуск продукции сократился более чем в 20 раз [3], на Йошкар-Олинском машиностроительном заводе более чем в 30 раз [1] и так по всей лесной машиностроительной отрасли. На сегодняшний день в лесозаготовительной отрасли реально наблюдается дефицит техники. В этой связи большой интерес для исследования представляет

\footnotetext{
${ }^{1}$ Автор - аспирант кафедры тяговых машин (C) А. В. Занин, 2003
}

анализ производственных программ ведущих российских заводов - производителей лесных тракторов.

Одной из первых модификаций, разработанных Онежским тракторным заводом, а впоследствии ставших базой для многооперационных машин, является лесопромышленный трактор ТДТ-55А (рис.1). На тракторе установлен дизельный двигатель с турбонаддувом, пятиступенчатая механическая коробка передач. Главная передача, механизмы поворота с тормозами, бортовые передачи, объединенные в один блок, составляют задний мост трактора. В качестве механизма поворота применены две дисковые муфты сухого трения постоянно замкнутого типа. ТДТ-55А имеет 4-катковую ходовую систему, рычажнобалансирную с пружинным подрессориванием подвеску. Гусеничная цепь состоит из стальных литых траков, соединенных шарнирно пальцами. Трактор ТДТ-55А-05 унифицирован с трактором ТДТ-55А и отличается от него только маркой дизеля. Модификацией трактора ТДТ-55А является трактор лесохозяйственный гусеничный ЛХТ-55, предназначенный для механизации лесовосстановительных работ на участках с переувлажненными почвами и пересеченным рельефом. Может быть использован на очистке вырубок, при борьбе с лесными пожарами и трелевке древесины. Машина оборудована опрокидывающимся на сторону самосвальным кузовом и имеет специальную навесную систему с валом отбора мощности. Технические характеристики не изменились.

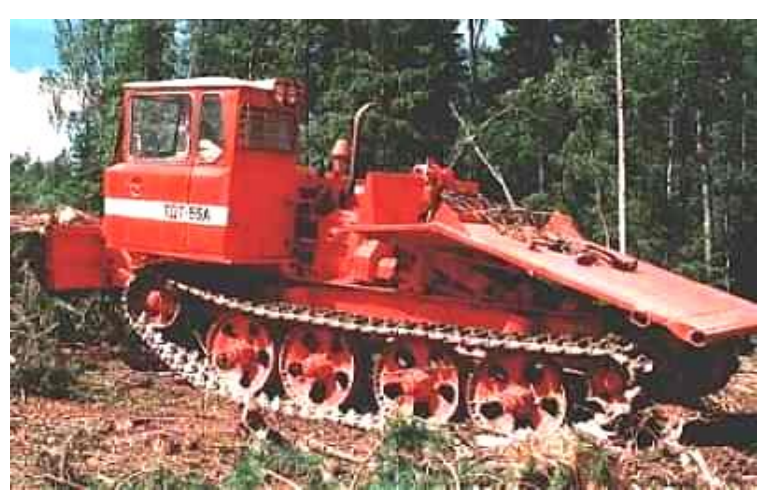

Рис. 1. Лесопромышленный трактор ТДТ-55А

Для создания нового поколения машин заводом в качестве базовой модели был разработан лесопромышленный гусеничный трактор ТЛТ-100 (рис. 2). На тракторе установлены дизельный двигатель с турбонаддувом, усиленная рама, пятиступенчатая коробка передач с шестернями постоянного зацепления и муфтами переключения, ведущий мост с неразъемным картером бортовой передачи, унифицированные раздельные гидроусилители управления трактором. Ходовая система - 4-катковая, подвеска рычажнобалансирного типа с пружинным подрессориванием.

Унифицированный трактор ТЛТ-100А отличается от ТЛТ-100 маркой дизеля (Д-245-16Л) и сохраняет без изменения его технические характеристики (табл.1). 


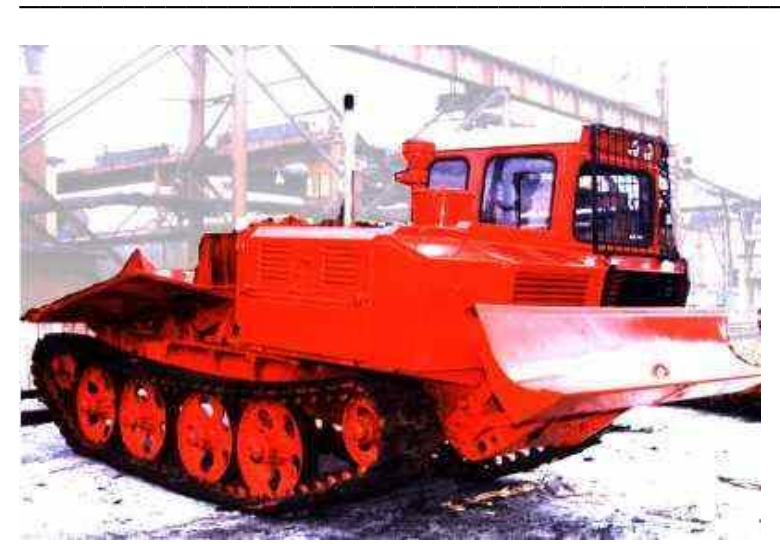

Рис. 2. Трактор лесопромышленный гусеничный ТЛТ-100

Таблица 1

Технические характеристики трактора ТЛТ-100

\begin{tabular}{|c|c|}
\hline Марка дизеля & СМД- 20Т.04 \\
\hline Габаритные размеры, мм & $6000 * 2575 * 3000$ \\
\hline Дорожный просвет, мм & 555 \\
\hline $\begin{array}{c}\text { Максимальный объём тре- } \\
\text { люемого пакета, куб.м }\end{array}$ & 10 \\
\hline $\begin{array}{c}\text { Наибольшее из средних } \\
\text { давлений гусениц на грунт, } \\
\text { МПа }\end{array}$ & 0,049 \\
\hline Ширина гусеницы, мм & 440. \\
\hline
\end{tabular}

Модификацией трактора ТЛТ-100 является трактор лесопромышленный гусеничный ТЛТ-100-06 (рис.3). Основной отличительной чертой является применение ведущего моста с двухступенчатой бортовой передачей и новой ходовой системы повышенной проходимости. Новая ходовая система отличается от базовой применением более широких гусениц (640 мм по сравнению с 440 мм на ТЛТ-100) и опущенной ведущей звездочкой. Использование на тракторе увеличенной опорной поверхности гусениц и опущенной ведущей звездочки значительно увеличивает площадь контакта трактора с лесной почвой, что привело к значительному уменьшению удельного давления на грунт (0,030 МПа по сравнению с 0,049 МПа у ТЛТ100). Благодаря этому трактор можно использовать на грунтах с низкой несущей способностью. Трактор ТЛТ-100-04 унифицирован с трактором ТЛТ-100-06 и отличается от него только шириной гусениц (480 мм).

Модификацией ТЛТ-100-06 является созданная на его базе трелевочная машина (пачкоподборщик) ЛТ230 (рис.4), предназначенная для подбора и трелевки пачек деревьев, сформированных валочнопакетирующими машинами, а также для уплотнения штабелей деревьев (хлыстов) и выравнивания комлей.

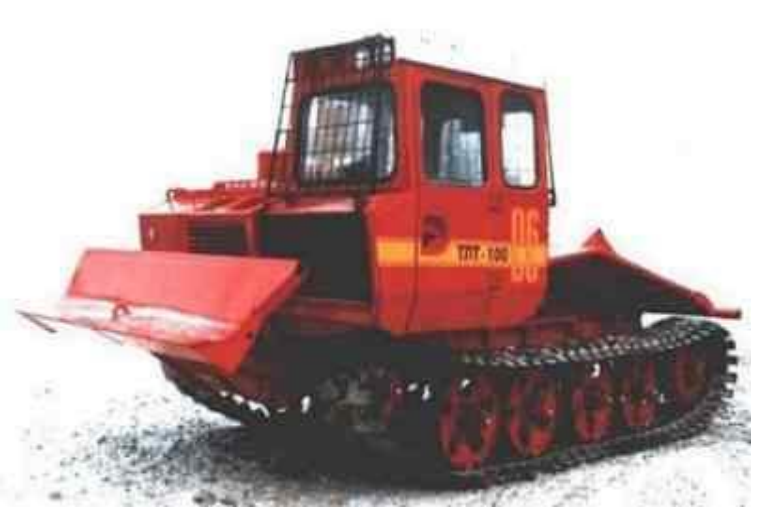

Рис. 3. Трактор лесопромышленный гусеничный ТЛТ-100-06

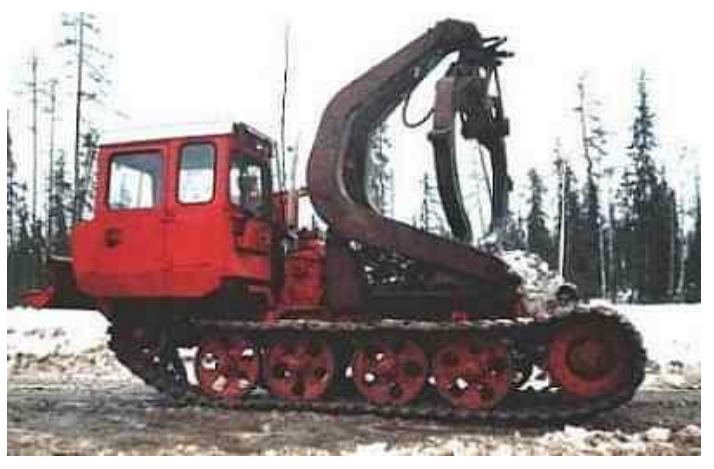

Рис. 4. Трелевочная машина (пачкоподборщик) ЛТ-230

Разработанная заводом гусеничная машина ТБ-1М-15 (рис. 5) позволяет производить бесчокерную трелевку леса и является базовой моделью машин нового поколения.

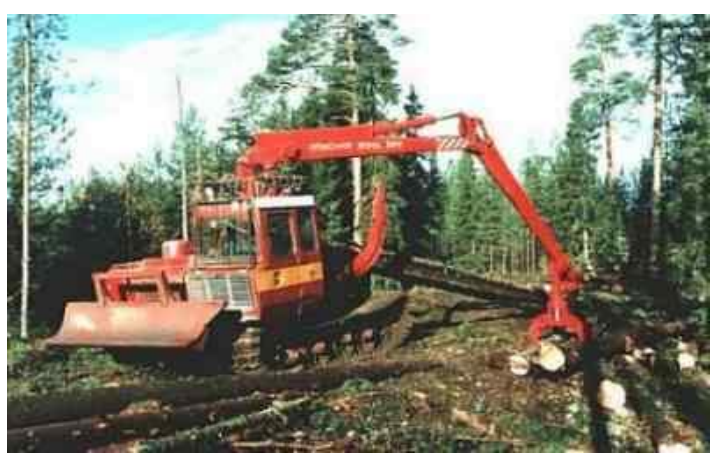

Рис. 5. Машина гусеничная для бесчокерной трелевки леса ТБ-1М-15

Машина гусеничная для бесчокерной трелевки леса ТБ-1М-08 унифицирована с ТБ-1М-15 и отличается от нее шириной гусениц (640 мм в сравнении с 480 мм). Технические характеристики приведены в табл. 2. 
Таблица 2

Технические характеристики ТБ-1М-15 и ТБ-1М-08

\begin{tabular}{|c|c|c|}
\hline Показатели & ТБ-1М-15 & ТБ-1М-08 \\
\hline Марка дизеля & СМД-20Т.04 & СМД-20Т.04 \\
\hline $\begin{array}{c}\text { Мощность ди- } \\
\text { зеля, кВт (л.с.) }\end{array}$ & $88(120)$ & $88(120)$ \\
\hline $\begin{array}{c}\text { Максимальный } \\
\text { объём трелю- } \\
\text { емого пакета, } \\
\text { куб.м }\end{array}$ & $\begin{array}{c}8 \text { за комли } \\
10 \text { за вершины }\end{array}$ & $\begin{array}{c}8 \text { за комли } \\
10 \text { за вершины }\end{array}$ \\
\hline $\begin{array}{c}\text { Масса эксплуа- } \\
\text { тационная, кг }\end{array}$ & 14400 & 14200 \\
\hline $\begin{array}{c}\text { Наибольшее из } \\
\text { средних давле- } \\
\text { ний гусениц на } \\
\text { грунт, МПа }\end{array}$ & 0,044 & 0,058 \\
\hline $\begin{array}{c}\text { Максимальный } \\
\text { вылет захвата } \\
\text { манипулятора, } \\
\text { м }\end{array}$ & 8 & 8 \\
\hline $\begin{array}{c}\text { Ширина гусе- } \\
\text { ницы, мм }\end{array}$ & 640 & $7070 * 2780 * 3700$ \\
\hline $\begin{array}{c}\text { Габаритные } \\
\text { размеры: дли- } \\
\text { на*ширина*вы- } \\
\text { сота }\end{array}$ & $7070 * 2760 * 3700$ \\
\hline
\end{tabular}

Все возрастающие объемы заготовок леса с помощью сортиментной технологии привели к необходимости разработки и выпуска заводом машины погрузочнотранспортной (сортиментовоз) ТБ-1М-16 (рис.6), она является модернизацией машины для бесчокерной трелевки леса ТБ-1М-15. Данная машина предназначена для сбора, погрузки, транспортировки и разгрузки сортиментов при перемещении их с лесосеки на промежуточный склад, а также выполнения операций сортировки по породам и длинам в процессе погрузки, разгрузки и складирования сортиментов.

Еще одной перспективной разработкой Онежского тракторного завода является валочно-пакетирующая машина ТЛГ 3-12 (рис.7), которая осуществляет спиливание деревьев и укладку их в пачки. В составе системы машин, реализующей технологический процесс заготовки и вывозки из лесосеки длинномерных хлыстов, ТЛГ 3-12 может быть использована как на сплошных рубках главного пользования, так и на рубках ухода и прореживания, разрубке трасс под линии электропередач, при строительстве дорог. Низкое давление на грунт обеспечивается конструкцией ходовой системы повышенной проходимости, что позволяет машине работать на грунтах с низкой несущей способностью и глубоком снегу.

Необходимо отметить, что новые машины семейства «Онежец», по сравнению с серийно выпускаемыми ТДТ-55А и ТБ-1, передают значительно меньшее давление на грунт.

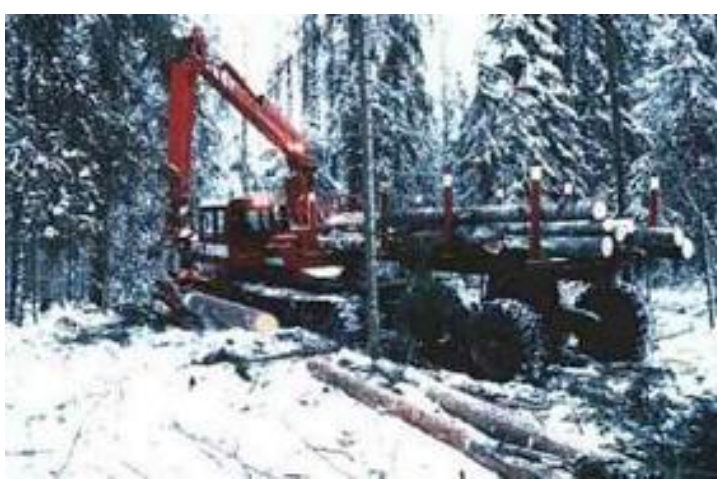

Рис. 6. Погрузочно-транспортная машина (сортиментовоз) ТБ-1М-16

Так, у новых машин с тросочокерным оборудованием наибольшее из средних давлений снизилось в $1,37 \ldots 1,47$ раза по сравнению с ТДТ-55А, у бесчокерных - в $1,48 \ldots 2,1$ раза по сравнению с ТБ-1, несмотря на увеличение в целом эксплуатационной массы новых машин [4].

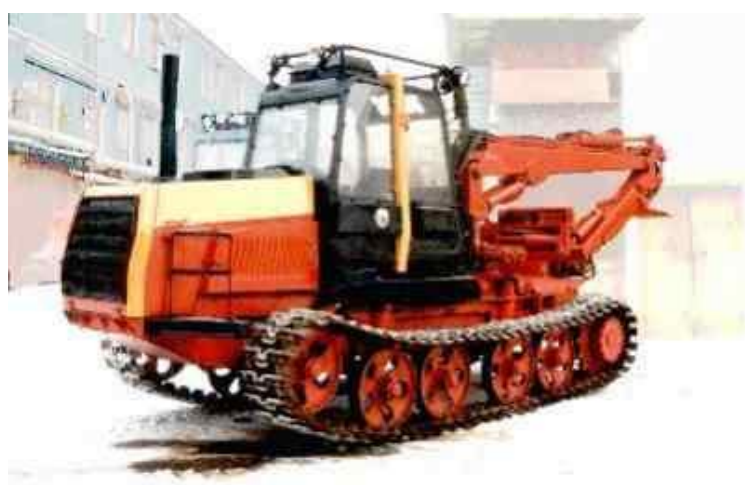

Рис. 7. Валочно-пакетирующая машина ТЛГ 3-12

Выпуском лесозаготовительной техники на базе тракторов ОТЗ занимаются и другие производители. Так, на базе ОАО «Экспериментальный механический завод» (г. Химки) выпущена универсальная машина для заготовки деревьев (хлыстов). Опытный образец был изготовлен в ноябре 2002 г. и прошел испытания в заводских условиях. Данная универсальная машина производится на базе серийного трактора ТБ-1М-15 (ОАО «Онежский тракторный завод»), машина оборудована гидроманипулятором, валочно-срезающим устройством, монтируемым на конце гидроманипулятора, зажимающим коником, толкателем и электрогидравлической системой управления. Машина может применяться для рубок главного и промежуточного пользования на местности с уклонами до $15^{\circ}$, при снежном покрове до 100 м, при температуре окружающей среды до $-40^{\circ} \mathrm{C}$.

Другим ведущим машиностроительным заводом в лесной отрасли наряду с Онежским тракторным является ОАО «Алтайский трактор». Завод выпускает несколько марок гусеничных лесозаготовительных тракторов. 
Техническая характеристика универсальной машины Л3-3

\begin{tabular}{|l|c|}
\hline Мощность двигателя, кВт (л. с.) & 88 \\
\hline $\begin{array}{l}\text { Грузовой момент гидроманипу- } \\
\text { лятора, кНм }\end{array}$ & 80 \\
\hline $\begin{array}{l}\text { Наибольший вылет манипуля- } \\
\text { тора, м }\end{array}$ & 7,5 \\
\hline $\begin{array}{l}\text { Угол поворота манипулятора, } \\
\text { град. }\end{array}$ & 250 \\
\hline $\begin{array}{l}\text { Наибольший диаметр срезаемо- } \\
\text { го дерева, мм }\end{array}$ & 650 \\
\hline Объем трелюемой пачки, куб. м & 8 \\
\hline Масса конструктивная , кг & 13300 \\
\hline Ширина траков, мм & 640 \\
\hline
\end{tabular}

Базовой моделью алтайских тракторов является гусеничный трактор ТТ-4М. В базовой комплектации трактор оснащен трелевочным оборудованием (реверсивной лебедкой и гидрофицированным погрузочным щитом) и предназначен для трелевки крупного и среднего леса в полупогруженном состоянии и укладывания его в штабеля. Для повышения эффективности использования на ТТ-4М-01 вместо обычно используемой гусеницы шириной 550 мм могут быть установлены гусеницы шириной 500 и 600 мм. Технические характеристики приведены в табл. 4

Модификация трактора ТT-4М-01 предназначена для использования в качестве тягово-транспортноэнергетического шасси машин различного назначения. Так, на его базе завод производит следующие модели тракторов: трелевочный с корчевательнособирательным оборудованием ТТ-4M-15, трелевочный с рыхлительным оборудованием ТТ-4М-16, трелевочный с толкателем ТТ-4М-04, машину трелевочную бесчокерную ЛТ-187 (рис. 8), лесопогрузчик челюстной ЛТ-188.

Следующим поколением гусеничных тракторов, заменяющим ТТ-4М, является машина МТ-5 (рис. 9), предназначенная для трелевки леса, она укомплектована реверсивной лебедкой и гидрофицированным погрузочным щитом.

MT-5 может быть оснащена дополнительным сменным рабочим оборудованием: толкателем; передней гидронавеской с установленными на ней прямым бульдозерным отвалом, поворотным (в плане) отвалом, клиновым отвалом или корчевательнособирательным отвалом; рыхлителем; самосвальным кузовом для насыпных и навалочных грузов массой до 5700 кг и объемом до $12,5 \mathrm{~m}^{3}$. Технические характеристики МТ-5 приведены в табл. 5.

На базе транспортно-энергетической машины МТ-5 разработана машина ЛТ-187А (рис. 10), которая является следующим поколением серийно изготавливаемой в настоящее время ЛТ-187.
Технические характеристики ТТ-4М

\begin{tabular}{|c|c|}
\hline Мощность двигателя, кВт (л. с.) & $95,5(130)$ \\
\hline $\begin{array}{l}\text { Удельный расход топлива, } \\
\text { г/кВт·ч }\end{array}$ & $227+8$ \\
\hline Тяговые усилия, кН & $116,1-15,6$ \\
\hline \multicolumn{2}{|l|}{$\begin{array}{l}\text { Среднее условное давление на } \\
\text { грунт (незаправленного тракто- } \\
\text { ра), кПа }\end{array}$} \\
\hline - TT-4M & 38 \\
\hline$\cdot$ TT-4M-01 & 33 \\
\hline Высота, мм & 2957 \\
\hline База, мм & 2880 \\
\hline Колея, мм & 2050 \\
\hline Ширина, мм & 2700 \\
\hline \multicolumn{2}{|l|}{ Длина, мм } \\
\hline$\cdot \mathrm{TT}-4 \mathrm{M}$ & 6070 \\
\hline$\cdot$ TT-4M-01 & 5927 \\
\hline \multicolumn{2}{|l|}{ Эксплуатационная масса, кг } \\
\hline - TT-4M & 14400 \\
\hline$\cdot$ TT-4M-01 & 12600 \\
\hline \multicolumn{2}{|l|}{$\begin{array}{l}\text { Максимальная грузоподъем- } \\
\text { ность, кН }\end{array}$} \\
\hline$\cdot \mathrm{TT}-4 \mathrm{M}$ & 68,7 \\
\hline$\cdot$ TT-4M-01 & 113,5 \\
\hline $\begin{array}{l}\text { Максимальная масса трелюемо- } \\
\text { го пакета, кг }\end{array}$ & 15000 \\
\hline
\end{tabular}

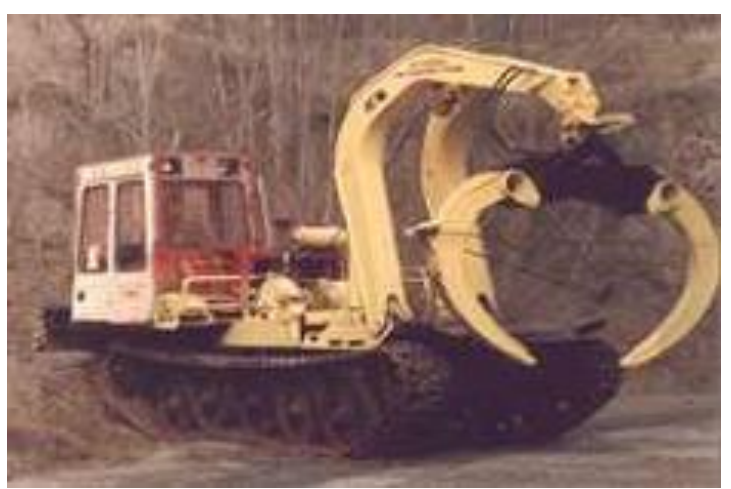

Рис. 8. Машина трелевочная бесчокерная ЛТ-187

Машина трелевочная бесчокерная ЛТ-187А предназначена для подбора пачек деревьев объемом до $10 \mathrm{~m}^{3}$, подготовленных валочно-пакетирующими машинами, и их трелевки. На ЛТ-187А используются уширенные гусеницы с резинометаллическим шарниром, что позволяет использовать машину на грунтах с низкой несущей способностью, т.к. уменьшается удельное давление на лесную почву. Машина может производить ряд подготовительно-вспомогательных работ: выравнивание торцов комлей хлыстов на погрузочной площадке; поперечное перемещение деревьев с целью подачи их в зону работы сучкорезной машины; удаление сучьев от сучкорезной машины толкателем или перемещение их в захвате. Технические характеристики представлены в табл. 6 . 


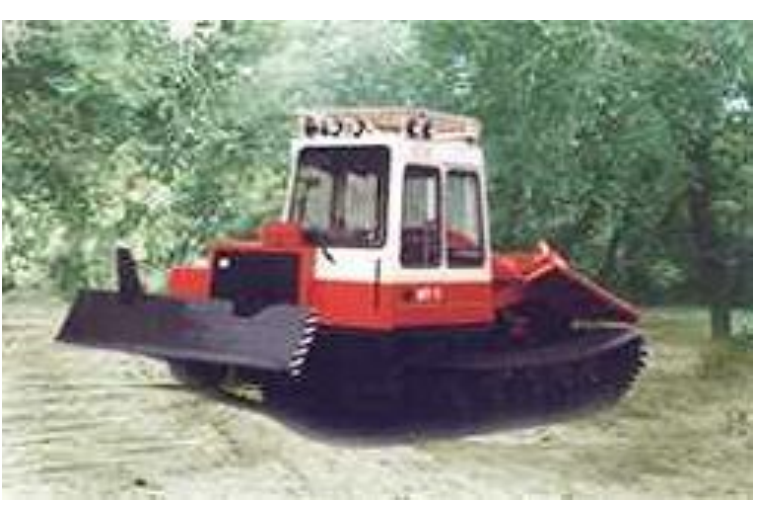

Рис. 9. Транспортно-энергетическая машина МТ-5

Таблица 5

Технические характеристики МТ-5

\begin{tabular}{|l|c|}
\hline $\begin{array}{l}\text { Максимальная масса } \\
\text { трелюеог пакета, кг }\end{array}$ & 16000 \\
\hline $\begin{array}{l}\text { Максимальная грузо- } \\
\text { подъемность погрузоч- } \\
\text { ного устройства, кН }\end{array}$ & 73,6 \\
\hline $\begin{array}{l}\text { Максимальная грузо- } \\
\text { подъемность шасси, кН }\end{array}$ & 117,7 \\
\hline $\begin{array}{l}\text { Скорости движения, } \\
\text { мсс }\end{array}$ & $0,69-3,1$ \\
\hline $\begin{array}{l}\text { Среднее условное дав- } \\
\text { ление на грунт, кПа: }\end{array}$ & \\
\hline •машины & 35 \\
\hline • шасси & 29,4 \\
\hline $\begin{array}{l}\text { Габаритные размеры, } \\
\text { мм }\end{array}$ & \\
\hline •длина & 7065 \\
\hline • ширина & 2750 \\
\hline$\bullet$ высота & 3171 \\
\hline Масса машины, кг & 14520 \\
\hline
\end{tabular}

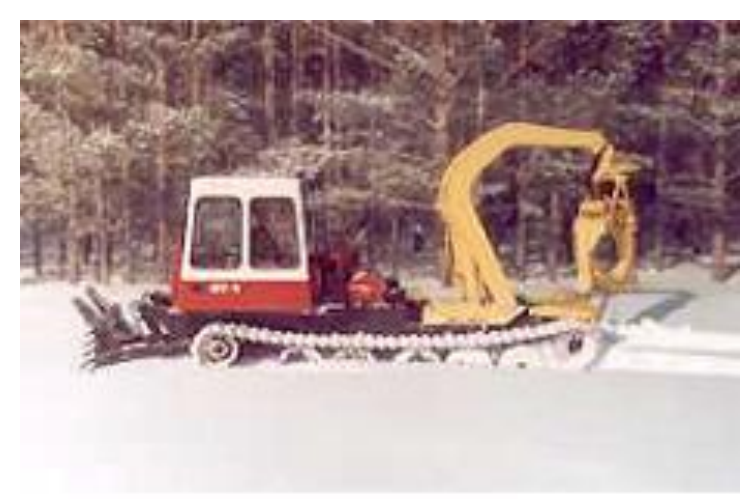

Рис. 10. Трелевочная бесчокерная машина ЛТ-187А

Кроме этих двух машин на лесозаготовительных предприятиях России уже используются или осваиваются гусеничные скиддеры Ковровского машиностроительного завода МЛ-136 и МЛ-230 (ЛТ-89Б). Технические характеристики приведены в табл. 8.
Таблица 6

Технические характеристики ЛТ-187А

\begin{tabular}{|l|c|}
\hline \multicolumn{1}{|c|}{$\begin{array}{c}\text { Технические } \\
\text { характеристики }\end{array}$} & \multicolumn{1}{c|}{$\begin{array}{c}\text { Значения } \\
\text { параметров }\end{array}$} \\
\hline $\begin{array}{l}\text { Наибольший объем } \\
\text { трелюемой пачки, м }\end{array}$ & 10 \\
\hline $\begin{array}{l}\text { Средняя скорость дви- } \\
\text { жения с грузом, км/ч, } \\
\text { не менее }\end{array}$ & 4,3 \\
\hline $\begin{array}{l}\text { Среднее давление на } \\
\text { грунт (статическое), } \\
\text { кПа, не более }\end{array}$ & 50 \\
\hline $\begin{array}{l}\text { Конструктивная масса } \\
\text { навесного оборудова- } \\
\text { ния, кг, не более }\end{array}$ & 3550 \\
\hline $\begin{array}{l}\text { Средний ресурс до } \\
\text { первого капремонта по } \\
\text { мотосчетчику, ч, не } \\
\text { менее }\end{array}$ & 4500 \\
\hline
\end{tabular}

Приведенный анализ техники, производимой в настоящее время, показывает, что большинство отечественных машин - гусеничные. Это обусловлено произведственно-эксплуатационными условиями использования лесозаготовительных машин, т.к. большую часть почв, на которых производятся вырубки, составляют грунты с низкой несущей способностью.

Таблица 7

Технические характеристики МЛ-135 и МЛ-119А

\begin{tabular}{|c|c|c|}
\hline Показатели & МЛ-135 & МЛ-119А \\
\hline $\begin{array}{l}\text { Ширина гусеничной } \\
\text { ленты, мм }\end{array}$ & 750 & 600 \\
\hline $\begin{array}{l}\text { Ширина по гусеничной } \\
\text { ходовой тележке, м }\end{array}$ & 3,2 & 3,1 \\
\hline $\begin{array}{c}\text { Вылет манипулятора, м: } \\
\text { наибольший } \\
\text { наименьший }\end{array}$ & $\begin{array}{c}9,4 \\
\text { Рабочий орган }\end{array}$ & $\begin{array}{c}9,2 \\
4,1\end{array}$ \\
\hline $\begin{array}{c}\text { пильным с } \\
\text { диском и } \\
\text { накопителем }\end{array}$ & $\begin{array}{c}\text { пильной } \\
\text { цепью }\end{array}$ \\
\hline $\begin{array}{c}\text { Наибольший диаметр } \\
\text { срезаемого дерева, м }\end{array}$ & 0,56 & 0,90 \\
\hline $\begin{array}{c}\text { Грузоподъемность при } \\
\text { наибольшем вылете } \\
\text { манипулятора, т }\end{array}$ & 1,80 & 2,50 \\
\hline $\begin{array}{c}\text { Среднее статистиче- } \\
\text { ское давление на грунт, } \\
\left.\text { мПа (кг/см }{ }^{2}\right)\end{array}$ & $\begin{array}{c}0,044 \\
(0,44)\end{array}$ & $\begin{array}{c}0,07 \\
(0,7)\end{array}$ \\
\hline Мощность, кВт (л.с.) & $165(225)$ & $125(170)$ \\
\hline
\end{tabular}

Кроме того, в условиях сложившихся экономических трудностей ведущие заводы вынуждены свертывать перспективные программы и вести выпуск более дешевых и простых машин. При этом обостряются вопросы, связанные с проходимостью и экологической 
совместимостью гусеничных движителей с почвогрунтами. В этой связи основные усилия должны быть направлены на улучшение экологической совместимости выпускаемой лесозаготовительной техники.

Таблица 8

Технические характеристики МЛ-136 и МЛ-230

\begin{tabular}{|c|c|c|}
\hline Показатели & МЛ-136 & $\begin{array}{l}\text { МЛ-239 } \\
(Л Т-89 Б)\end{array}$ \\
\hline $\begin{array}{c}\text { Наибольшее из сред- } \\
\text { них удельных давле- } \\
\text { ний на грунт, МПа } \\
\text { (кг/см) }\end{array}$ & $0,035(0,35)$ & $\begin{array}{c}0,035(0,35 \\
)\end{array}$ \\
\hline \begin{tabular}{|c} 
Габаритные размеры, мм: \\
длина \\
ширина \\
высота \\
\end{tabular} & $\begin{array}{l}6000 \\
2800 \\
3860\end{array}$ & $\begin{array}{l}6200 \\
2760 \\
3820\end{array}$ \\
\hline $\begin{array}{c}\text { Трелевочное оборудо- } \\
\text { вание, пачковый за- } \\
\text { хват }\end{array}$ & $\begin{array}{c}\text { Поворотная } \\
\text { платформа, } \\
\text { пачковый } \\
\text { захват }\end{array}$ & $\begin{array}{c}\text { Стрела, } \\
\text { пачковый } \\
\text { захват на } \\
\text { тросовой } \\
\text { подвеске, } \\
\text { лебедка } \\
\text { для за- } \\
\text { крытия } \\
\text { захвата }\end{array}$ \\
\hline $\begin{array}{c}\text { Максимальный объем } \\
\text { трелюемой пачки, }^{3}\end{array}$ & 7,0 & 7,0 \\
\hline $\begin{array}{c}\text { Площадь сечения за- } \\
\text { хвата при максималь- } \\
\text { ной пачке, } \text { м }^{2}\end{array}$ & 1,3 & 1,8 \\
\hline $\begin{array}{c}\text { Наибольший вылет } \\
\text { захвата от оси веду- } \\
\text { щих колес, мм }\end{array}$ & 1650 & 1630 \\
\hline $\begin{array}{c}\text { Угол поворота захва- } \\
\text { та, град. }\end{array}$ & Неогранич. & - \\
\hline
\end{tabular}

\section{СПИСОК ЛИТЕРАТУРЫ}

1. Карелия в 1991 - 1998 гг. Анализ социальноэкономического положения Республики Карелия / Карельский научный центр РАН. Петрозаводск, 1999. 113 c.

2. Кулапин Р. П. Оценка состояния и прогноз развития российского рынка тракторов // Тракторы и сельскохозяйственные машины. 1999. № 1 . C. 2-5.

3. Герасимов Ю. Ю., Костюкевич В. М., Гершеев А. С. Анализ положения в лесном машиностроении и меры по техническому обеспечению ЛПК промышленными предприятиями Карелии // Труды лесоинженерного факультета ПетрГУ. Вып. 3. Петрозаводск, 2001. С. 24-29.

4. Федосеев О. В., Куликов М. И. Машины ОАО «ОТЗ» - машины нового поколения // Труды лесоинженерного факультета ПетрГУ. Вып. 3. Петрозаводск, 2001. С. 92-95. 